\title{
Occurrence of Multi-Drug Resistant Escherichia Coli and Escherichia Coli O 157:H7 in Meat and Swab Samples of Various Contact Surfaces at Abattoir and Butcher Shops in Jimma Town, Southwest District of Ethiopia
}

This article was published in the following Dove Press journal: Infection and Drug Resistance

\section{Mengistu Abayneh Sebsibe Eyob Tekalign Asfaw}

School of Medical Laboratory Sciences, Mizan-Tepi University, Mizan Teferi, Ethiopia
Correspondence: Mengistu Abayneh Sebsibe

Email menge.abay@gmail.com
Background: Raw meat is one of the commonly consumed traditional diets in Ethiopia. However, unhygienic processing and distribution practices are risky for contamination of meat leading to human infection. This study was conducted to assess the presence of multidrug resistant $E$. coli with special emphasis on E. coli $\mathrm{O} 157: \mathrm{H} 7$ from meat of cattle and swab samples at abattoir houses and butcher shops in Jimma town, Southwest district of Ethiopia. Methodology: A cross-sectional descriptive study was conducted from April to July, 2018. The isolation and identification processes passed through enrichment of samples with modified tryptone soy broth (mTSB), streaked onto MacConkey agar and Cefixime-tellurite sorbitol MacConkey agar, biochemical testing (indole and TSI), followed by latex agglutination testing. Results: Out of 505 samples, 102 (20.2\%) and 27 (5.4\%) were positive for E. coli and E. coli O157:H7, respectively. Of these, $55(19.3 \%)$ and $47(21.4 \%)$ of $E$. coli and $17(6.0 \%)$ and 10 (4.5\%) of E. coli $\mathrm{O} 157: \mathrm{H} 7$ were isolated from the abattoir and butcher shop samples, respectively. A significant difference in the occurrences was observed among sample sources. Antimicrobial susceptibility test results showed that, $92.2 \%$ to $96.1 \%$ of E. coli and $85.5 \%$ to $96.3 \%$ of $E$. coli O157:H7 were susceptible to third generation cephalosporin, ciprofloxacin, gentamycin, kanamycin, streptomycin, and chloramphenicol. About $91.2 \%$ and $97.1 \%$ of $E$. coli and $88.9 \%$ and $92.6 \%$ of $E$. coli $0157: \mathrm{H} 7$ were resistant to ampicillin and erythromycin, respectively. A total of $57(44.2 \%)$ E. coli and E. coli $\mathrm{O} 157: \mathrm{H} 7$ isolates were resistant to three or more classes of antibiotics. All abattoir and butcher shop workers did not have any formal education or training certificates on food safety, and unhygienic practices were also observed. Conclusion: The presence of $E$. coli and E. coli $\mathrm{O} 157: \mathrm{H} 7$ including multi-drug resistant isolates in raw meat highlights how the current meat processing and distribution practice was unhygienic. Therefore, strategies in the prevention and control of food-borne infections that could be caused by multi-drug resistant strains will depend greatly on hygienic processing and distribution practices of meat.

Keywords: multi-drug resistant E. coli and E. coli O157:H7, abattoir and butcher shops, Jimma town

\section{Background}

Escherichia coli are a member of the family Enterobacteriaceae, and are normal inhabitants of the gastrointestinal tract of animals and humans. Some strains, such 
as shiga toxin-producing enterohemorrhagic $E$. coli (EHEC) O157:H7 is the predominant and most virulent serotype associated with bloody and non-bloody diarrhea, hemorrhagic colitis and hemolytic uremic syndrome (HUS). ${ }^{1,2}$ Ruminants are said to be reservoirs, whereby cattle are regarded as principal sources of infections. Ingestion of $E$. coli $\mathrm{O} 157: \mathrm{H} 7$ with contaminated food products of animal origins and following contact with infected animals or the contaminated environment has led to human infection. ${ }^{3,4}$

In the past two decades, isolation of the pathogens, including STEC O157:H7 from animals, food, clinical samples, and the environment has been reported from all continents. ${ }^{5}$ Globally, STEC O157:H7 causes 2, 801, 000 acute illnesses annually, with an incidence rate of 43.1 cases per 100,000 persons per year. ${ }^{5}$ Among those, a total of 10,200 cases of STEC infections occur in Africa with an incidence rate of 1.4 cases per 100,000 people per year. ${ }^{5}$ Ruminants, particularly cattle and sheep, seem to be the maintenance hosts for EHEC O157:H7. ${ }^{6}$

In developing countries, animals are commonly slaughtered and dressed under unhygienic conditions and this further compromises the microbiological quality and safety of the meat obtained from the animals. ${ }^{7,8}$ For instance, fecal carriage of E. coli $\mathrm{O} 157: \mathrm{H} 7$ in animals provides the potential for these organisms to enter the food chain via fecal contamination of milk, contamination of meat with intestinal contents during slaughter or contamination of fruit and vegetables by contact with contaminated manure. During slaughter, the pathogen may be present on the skin or in the feces of the animal, and may get transferred to the carcass during evisceration or skin removal. Therefore, poor slaughter processes, particularly poor hygienic practices during slaughtering, transport and display of meat play a large role in increasing meat contamination. Thus, hygienic management of animal and their food products, especially during slaughtering and display of meat for sale remains a better option in the control of E. coli $\mathrm{O} 157$ transmission.

Additionally, antimicrobial resistance among enteric bacteria is an increasing global public health concern. In Ethiopia also, the occurrence of E. coli, including multidrug resistance in foods of animal origin is arguably high due to many reasons like unhygienic slaughtering practices in the abattoirs, illegal slaughtering of animals in open fields, poor meat transport, and display conditions at butcher shops. ${ }^{9,10}$ In addition, indiscriminate use of antimicrobial agents for growth promotion in livestock and for treatment of diseased animals may lead to the development of considerable resistant bacterial strains, in which it can be transmitted to humans through the food chain. ${ }^{11}$ This may pose a potential risk for the occurrence of foodborne disease because of a widespread tradition of raw meat consumption in our country.

There is a need to investigate the possible sources of STEC O157:H7 and to quantify risk factors to ensure that, prevention and control strategies are appropriate. However, in Ethiopia, the precise attribution of animals and their food products as the sources of resistant strains, and the consequences of it on human health have not yet been seriously evaluated. Therefore, this study was conducted to assess the presence of multi-drug resistant Escherichia coli with special emphasis on Escherichia coli $\mathrm{O} 157: \mathrm{H} 7$ from meat of cattle, cecal contents of slaughtered animals and swabs of contact surfaces at abattoir houses and butcher shops in Jimma town, Southwest district of Ethiopia.

\section{Methodology Study Area and Period}

This study was conducted in Jimma town, Southwest district of Ethiopia from April to July, 2018. Jimma town is located at $346 \mathrm{~km}$, Southwest of Addis Ababa, capital city of Ethiopia. The town is divided into 17 administrative kebeles. According to the information obtained from Jimma town trade and industry office, at the time of this study, there was one municipality abattoir which gives a slaughtering service to provide raw meat for around 80 officially registered butcher shops and for one government university cafeteria in the town.

\section{Study Design and Sampling}

A cross-sectional study was conducted and apparently healthy slaughtered cattle $(n=90)$ in Jimma municipal abattoir were selected randomly. Samples collected at the abattoir included; meat $(n=90)$ and cecal contents of slaughtered animals $(n=90)$, swabs from abattoir environments (eviscerator's knife $(n=20)$ and hands $(n=30)$, cutting boards $(n=20)$, transporter clothes $(n=20)$ and meat transport vehicles $(n=15))$, whereas from the butchers shops, meat $(n=90)$ and swab samples of knife $(n=30)$, butcher's hand $(n=40)$, cutting board $(n=30)$ and protective cloths $(n=30)$ were collected over a period of 8 weeks. Sampling points in the abattoir and at butcher shops were selected according to the problem areas in the process (after dehiding, after evisceration and after 
display for sale). To collect the data, one visit to the municipal abattoir and all officially registered butcher shops $(n=80)$ were made per week (on Saturday) for a consecutive 8 weeks. The reason is that the numbers of slaughtered animals were increased on Saturday; because, most local people prefer to buy and eat raw meat at the weekend.

\section{Collection of Samples Meat Sample Collection}

During the visit, a total of 180 meat samples (90 from abattoir house and the other 90 from butcher shops) were collected from different parts of the carcasses (abdomen [flank], thorax (lateral) and breast (lateral), brisket and crutch) at abattoir house and from whole cuts of raw meat at butcher shops as per the International Organization for Standardization (ISO). ${ }^{12}$ A total of 25 $\mathrm{g}$ of meat were taken from the relevant places of the carcasses at abattoir house and from whole cuts of raw meat at butcher shops using sterile scalpels and forceps and put into a sterile, separately labeled plastic bag and each pooled meat sample was thoroughly homogenized. Meat samplings were made after the removal (evisceration) of the gastrointestinal tract and after displayed for sale at butcher shops. After each sampling, separate scalpel and forceps were cleaned with pieces of gauze dipped in $70 \%$ ethanol to minimize cross-contaminations.

\section{Cecal Content Collection}

Ten gram (10 g) of cecal content was collected from 90 slaughtered cattle using sterile, wide mouthed and leak proof containers immediately after evisceration. Incision of the cecum was made with sterile surgical blade and fecal material was aseptically compressed to obtain a representative sample of the cecal content. All the collected samples were transported to the laboratory in a cool box on ice and analyzed within 24 hours of sampling.

\section{Environmental Samples Collection}

A total of 235 swab samples (105 from the abattoir and 130 from butcher shops) were collected from the hands of meat handlers, their protective clothing, knives and chopping boards after eviscerations at abattoir house and during the beginning of the operation at the butcher shops. In addition, swab samples were taken from vehicles used for distribution of meat to different butcher shops. The swab samples were taken from $15-20 \mathrm{~cm}^{2}$ of meat surface contact using sterile, buffered peptone water moistened cotton swabs. All the collected samples were labeled, packaged in sterile, separate containers and carried to the microbiology laboratory of Jimma University in a cold box immediately after collection for processing.

\section{Data on Hygienic Practices of Abattoir and Butcher Shop Workers}

Data on hygienic practices of abattoir and butcher shop workers were collected with a structured checklist and by direct observations. During the visits, about 15 from abattoir house and 30 butcher shop workers were checked as to whether they had educational and training certificates on food safety or not. In addition, the workers were checked as to whether their meat processing and handling practices were safe or not by using observational checklists. Data related to educational levels of meat processors and availability of clean tap water, regular hand washing and disinfection practice of hands, the floor and processing tools and vehicles before and during their work, whether they used clean protective cloths, whether they used separate, washable chopping boards and knives for processing of abdominal organs and other parts of meat, whether the same buckets of water were used for cleaning knives, washing hands, and whether fisting was done with most care to avoid carrying dirt were checked.

\section{Isolation and Identification Process Enrichment Processes}

From 25-g meat samples, $10 \mathrm{~g}$ each was weighed and enriched into an Erlenmeyer flask containing $90 \mathrm{~mL}$ of modified tryptone soya broth (mTSB) (Oxoid Ltd., Hampshire, UK) and incubated at $37^{\circ} \mathrm{C}$ for 24 hours. Similarly, all swab samples and $1 \mathrm{~g}$ of cecal contents from the slaughtered cattle was homogenized in $9 \mathrm{~mL}$ of mTSB and was incubated at $37^{\circ} \mathrm{C}$ for 24 hours. ${ }^{13}$

\section{Identification of the Isolates}

The overnight broth cultures were spread onto MacConkey agar and Sorbitol MacConkey agar (Oxoid Ltd., Hampshire, UK) supplemented with $0.05 \mathrm{mg} / \mathrm{l}$ Cefixime- $2.5 \mathrm{mg} / \mathrm{l}$ potassium tellurite. ${ }^{13}$ The inoculated plates were incubated at $37^{\circ} \mathrm{C}$ for 24 hours. The isolated colonies first were screened by colony morphology, color production (lactose fermenting pink colonies) and identified as E. coli by relevant biochemical tests, such as indole and triple sugar iron (TSI) tests. Three to five non- sorbitol fermenter, colorless with a small, round, weak pale brownish appearance E. coli O157:H7 suspect colonies were streaked onto non-selective media 
(ie, nutrient agar) and incubated at $37^{\circ} \mathrm{C}$ for 24 hours for confirmation by indole production and latex agglutination test kits (Oxoid Ltd., Hampshire, UK), following the manufacturer's instructions. From a pure culture on nutrient agar plates $1 \mu \mathrm{L}$ loop full were inoculated onto tryptophane medium and after overnight incubation of the plate at $37^{\circ} \mathrm{C}, 1 \mathrm{~mL}$ of the Kovacs reagent was added to the medium to confirm indole production (pink ring). Similarly, using a sterile wire loop, a single colony was taken and carefully emulsified in the drop of saline and then the suspension was mixed into the dry latex spots and spread to cover the reaction area. A result was positive if agglutination of the latex particles occurred within 1 minute. To be sure of the test results, first the isolates were tested with the control $\mathrm{O} 157$ latex reagent provided with the kit and then with $\mathrm{H} 7$ latex reagent. E. coli $O 157$ (CCUG 29889) and E. coli (ATCC25922) used as positive and negative control for reproducibility of Sorbitol MacConkey agar plates, respectively.

\section{Antibiotic Sensitivity Testing}

Antimicrobial susceptibility testing were done for all confirmed E. coli and E. coli O157:H7 isolates by using Kirby-Bauer disc diffusion technique for the following 13 antimicrobial agents (Oxoid Ltd., Hampshire, UK): cefotaxime (CTX, $30 \mu \mathrm{g}$ ), ceftriaxone (CRO, $30 \mu \mathrm{g}$ ), ceftazidime (CTZ, $30 \mu \mathrm{g})$, amoxicillin-clavulanic acid (AMC, 20/10 $\mu \mathrm{g}$ ), ampicillin (AMP, $10 \mu \mathrm{g}$ ), gentamicin (GEN,10 $\mu \mathrm{g}$ ), ciprofloxacin (CIP, $5 \mu \mathrm{g}$ ), erythromycin (ERY, $15 \mu \mathrm{g}$ ), trimethoprim-sulfamethoxazole (SXT, 1.25/23.75 $\mu \mathrm{g}$ ), tetracycline (TET,30 $\mu \mathrm{g})$ Kanamycin $(\mathrm{KAN}, 30 \mu \mathrm{g})$, chloramphenicol (CHL, $30 \mu \mathrm{g}$ ), and spectinomycin (STR, 100 $\mu \mathrm{g})$. First, the suspension was adjusted to $0.5 \mathrm{McFarland}$ 's standard. This suspension was inoculated onto MuellerHinton agar (MHA) and the above antimicrobial agents were placed using sterile forceps and pressed gently to ensure the contact of a medium. After overnight incubation of the plate at $37^{\circ} \mathrm{C}$, the zone of inhibition was measured by using sliding calipers and interpreted by comparing the zone of inhibition with the Kirby-Bauer chart as recommended by CLSI guidelines. ${ }^{14} \mathrm{E}$. coli ATCC*25922 were used as control strains to monitor accuracy and precision of identification and susceptibility testing procedures.

\section{Multi Drug Resistance (MDR)}

MDR is defined as a resistance of a bacterial strain for at least one agent in three or more antimicrobial classes. ${ }^{15}$

\section{Data Analysis}

The data were analyzed by using comprehensive metaanalysis version 3.3.070 software (www.Meta-analysis. com). Prevalence were expressed as the percent positive samples from total samples tested. Differences in the proportions of positive samples and multidrug resistance isolates between the samples sources (abattoir and butcher shops) and sample types (meat, cecal content and swab samples) were assessed statistically by using Z- testing and $p$-value $<0.05$ were considered as statistically significant.

\section{Results}

\section{Proportions of E. Coli and E. Coli OI57: H7 Positive Samples}

In this study, from the total of 505 samples, 102 (20.2\%) were confirmed as positive for $E$. coli and 27 (5.4\%) were positive for $E$. coli $\mathrm{O} 157: \mathrm{H} 7$ strains. With regard to sample sources, 55 (19.3\%) of E. coli and 17 (6.0\%) of E. coli O157: H7 were detected in abattoir house samples and 47 (21.4\%) and 10 (4.5\%) were detected from butcher shop samples, respectively. Accordingly, from abattoir house samples, E. coli was detected in $18(20.0 \%)$ of meat samples whereas, E. coli O157: $\mathrm{H} 7$ was detected in $4(4.4 \%)$ of the meat samples. From cecal content samples, E. coli was detected in 19 (21.1\%) and E. coli O157: $\mathrm{H} 7$ was detected in $9(10.0 \%)$. From the butcher shop samples, E. coli was detected in $26(28.9 \%)$ of meat samples, whereas E. coli $\mathrm{O} 157$ : $\mathrm{H} 75$ was found in $5(5.6 \%)$ of the meat samples. In addition, E. coli was detected in 5 (16.7\%) of the knife and 7 (23.3\%) of the cutting board swabs, whereas E. coli O157: H7 was detected in $1(5.0 \%)$ of the knife and $3(10.0 \%)$ of the cutting board swab samples, respectively. There was a statistically significant difference in the occurrence of E. coli and $E$. coli $\mathrm{O} 157: \mathrm{H} 7$ between sample types and sample sources $(p \leq 0.001)$ (Table 1$)$.

\section{Hygienic Practices of Abattoir and Butcher Shop Workers}

In this study, none of the slaughter staff and butchers had any form of formal educational certificate on food safety and any kind of short course training on safe practices in meat processing. In addition, none of abattoir and butcher shop workers wore clean protective clothing, and none of them were washing and disinfecting their hands, the processing tools and the floor after each working interval. The same cutting boards and knives were used for cutting of meat and abdominal organs. Slaughtering, flaying/dehiding and evisceration/fisting of animals were also taking 
Table I Proportions of E. Coli and E. Coli O I57: H7 Positive Samples Obtained from the Abattoir and Butcher Shops in Jimma Town, Southwest of Ethiopia

\begin{tabular}{|c|c|c|c|c|c|c|c|}
\hline \multirow{2}{*}{$\begin{array}{l}\text { Samples } \\
\text { Sources }\end{array}$} & \multirow[t]{2}{*}{ Types of Samples } & \multirow{2}{*}{$\begin{array}{l}\text { No. of } \\
\text { Samples Tested }\end{array}$} & \multicolumn{2}{|c|}{ No. of Positive Samples } & \multirow{2}{*}{$\begin{array}{l}\text { Positive/ } \\
\text { Sample } \\
\text { Tested }\end{array}$} & \multirow{2}{*}{$\begin{array}{l}\text { Prop. of Positives } \\
{[95 \% \mathrm{Cl}]}\end{array}$} & \multirow[t]{2}{*}{$p$-value } \\
\hline & & & $\begin{array}{l}\text { E. coli } \\
N(\%)\end{array}$ & $\begin{array}{l}\text { E. coli O I57: } \\
\text { H7 N (\%) }\end{array}$ & & & \\
\hline \multirow{8}{*}{$\begin{array}{l}\text { Abattoir } \\
\text { house }\end{array}$} & Meat sample & 90 & $18(20.0)$ & $4(4.4)$ & $22 / 90$ & $0.244[0.167,0.344]$ & 0.001 \\
\hline & Ceacal content & 90 & $19(2 \mathrm{I} .1)$ & $9(10.0)$ & $28 / 90$ & $0.31 I[0.224,0.414]$ & 0.001 \\
\hline & Hand swabs & 30 & $4(13.3)$ & I (3.3) & $5 / 30$ & $0.167[0.071,0.343]$ & 0.001 \\
\hline & Knives swabs & 20 & $4(20.0)$ & I (5.0) & $5 / 20$ & $0.250[0.108,0.478]$ & 0.033 \\
\hline & Cutting board swabs & 20 & $6(30.0)$ & $2(10.0)$ & $8 / 20$ & $0.400[0.2 \mid 4,0.620]$ & 0.374 \\
\hline & Protective cloth swabs & 20 & $2(10.0)$ & 0 & $2 / 20$ & $0.100[0.025,0.324]$ & 0.003 \\
\hline & Transport vehicles swab & 15 & $2(13.3)$ & 0 & $2 / 15$ & $0.133[0.034,0.504]$ & 0.014 \\
\hline & Sub-total N (\%) & 285 & $55(19.3 \%)$ & $17(6.0 \%)$ & $72 / 285$ & $0.253[0.206,0.306]$ & 0.001 \\
\hline \multirow{6}{*}{$\begin{array}{l}\text { Butcher } \\
\text { shops }\end{array}$} & Meat sample & 90 & $26(28.9)$ & $5(5.6)$ & $31 / 90$ & $0.344[0.254,0.448]$ & 0.004 \\
\hline & Hand swabs & 40 & $5(12.5)$ & 0 & $5 / 40$ & $0.125[0.053,0.567]$ & 0.001 \\
\hline & Knie swabs & 30 & $5(16.7)$ & $I(5.0)$ & $6 / 30$ & $0.200[0.093,0.379]$ & 0.002 \\
\hline & Cutting board swabs & 30 & $7(23.3)$ & $3(10.0)$ & $10 / 30$ & $0.333[0.190,0.516]$ & 0.074 \\
\hline & Protective cloth swabs & 30 & $4(13.3)$ & I (5.0) & $5 / 30$ & $0.167[0.071,0.343]$ & 0.001 \\
\hline & Sub-total N (\%) & 220 & $47(21.4 \%)$ & $10(4.5 \%)$ & $57 / 220$ & $0.259[0.205,0.321]$ & 0.001 \\
\hline \multicolumn{2}{|c|}{ Total N (\%) } & 505 & 102 (20.2\%) & 27 (5.4\%) & $129 / 505$ & $0.255[0.219,0.295]$ & 0.001 \\
\hline
\end{tabular}

place on the same floor without taking cares to avoid cross-contaminations. Moreover, the visceral organs were put very near to the carcass when displayed for sale or when meat was cut into pieces for selling or consumption. Most slaughter staff indicated that inadequate supplies of clean water posed a challenge towards maintaining hygiene (Table 2).

\section{Antibiotic Resistance Profile}

In this study, antimicrobial resistance testing was done against 13 different antimicrobial agents. Accordingly, E. coli and E. coli $\mathrm{O} 157: \mathrm{H} 7$ showed higher resistance against erythromycin and ampicillin with the prevalence of $(97.1 \%)$ and (92.6\%) and (91.2\%) and (88.9\%), respectively. Moreover, (38.2\%) and (36.3\%) E. coli and (40.7\%) and (44.4\%) E. coli O157: $\mathrm{H} 7$ were resistant to trimethoprimsulfamethoxazole and tetracycline, respectively. In contrast, (94.1\%) and (85.2\%) of E. coli and E. coli O157: $\mathrm{H} 7$ isolates were susceptible to cefotaxime, $(95.1 \%)$ and $(88.9 \%)$ to ceftriaxone, $(92.2 \%)$ and $(85.2 \%)$ to ceftazidime, $(96.1 \%)$ and $(96.3 \%)$ to ciprofloxacin, $(95.1 \%)$ and $(88.9 \%)$ to kanamycin, $(94.1 \%)$ and $(92.6 \%)$ to gentamycin, $(94.1 \%)$ and $(92.6 \%)$ to streptomycin and $(95.1 \%)$ and $(85.2 \%)$ to chloramphenicol, respectively (Table 3 ).

Table 2 Summary of Observational Checklist Results on Educational Level and Hygienic Practice of the Abattoir and Butcher Shop Workers in Jimma Town, Southwest Ethiopia

\begin{tabular}{|l|l|l|}
\hline Activities Observed and Checked & Abattoir House Workers & Butcher Shop Workers \\
\hline Having formal education certificate on food safety & $\begin{array}{l}\text { None of them } \\
\text { Having short course training on safe meat handling }\end{array}$ & $\begin{array}{l}\text { None of them } \\
\text { None of them } \\
\text { Use of protective clean clothing }\end{array}$ \\
Regular washing of hand and processing tools & $\begin{array}{l}\text { None of them } \\
\text { Regular disinfection of hand, the floor and processing tools }\end{array}$ & None of them \\
Is slaughtered animals flaying/dehiding and evisceration/ fisting on separate surface? & No & No \\
Fisting done with most care to avoid carrying dirt & No & None of them \\
Is there adequate supply of clean water? & None of them \\
Use of separate knives for cutting of meat and abdominal contents & Not checked \\
Use of separate chopping boards for cutting of carcass and abdominal organs & Not checked \\
Use of the separate buckets of water for cleaning knives, washing hands & Not \\
None of them \\
None of them \\
None of them
\end{tabular}


Table 3 Antimicrobial Resistance Patterns of E. Coli and E. Coli OI57: H7 Isolates in Different Samples from Abattoir and Butcher Shops in Jimma Town, Southwest of Ethiopia

\begin{tabular}{|c|c|c|c|c|c|c|}
\hline \multirow[t]{3}{*}{ Antimicrobial Disc (Code) } & \multicolumn{6}{|c|}{ Resistance Patterns } \\
\hline & \multicolumn{3}{|c|}{ E. coli $(n=102)$} & \multicolumn{3}{|c|}{ E. coli OI57: H7 $(n=27)$} \\
\hline & $\mathbf{S}(\%)$ & I (\%) & $\mathbf{R}(\%)$ & $\mathbf{S}(\%)$ & I (\%) & $\mathbf{R}(\%)$ \\
\hline Ampicillin (AMP) & $9(8.8)$ & 0 & $93(91.2)$ & $2(7.4)$ & I (3.7) & $24(88.9)$ \\
\hline Amoxicillin -clavulanic acid (AMC) & $66(64.7)$ & $3(2.9)$ & $33(32.4)$ & $17(63.0)$ & $2(7.4)$ & $8(29.6)$ \\
\hline Cefotaxime (CTX) & $96(94.1)$ & $3(2.9)$ & $3(2.9)$ & $23(85.2)$ & I (3.7) & $2(7.4)$ \\
\hline Ceftriaxone (CRO) & $97(95.1)$ & $2(2.0)$ & $4(3.9)$ & $24(88.9)$ & I (3.7) & $2(7.4)$ \\
\hline Ceftazidime (CTZ) & $94(92.2)$ & $3(2.9)$ & $5(4.9)$ & $23(85.2)$ & $2(7.4)$ & $2(7.4)$ \\
\hline Chloramphenicol (CHL) & $97(95.1)$ & 0 & $5(4.9)$ & $23(85.2)$ & I (3.7) & $3(11.1)$ \\
\hline Ciprofloxacin (CIP) & $98(96.1)$ & 0 & $3(2.9)$ & $26(96.3)$ & 0 & I (3.7) \\
\hline Erythromycin (ERY) & $3(2.9)$ & 0 & $99(97.1)$ & $2(7.4)$ & 0 & $25(92.6)$ \\
\hline Gentamicin (GEN) & $96(94.1)$ & $\mathrm{I}(\mathrm{I} .0)$ & $5(4.9)$ & $25(92.6)$ & I (3.7) & I (3.7) \\
\hline Kanamycin (KAN) & $97(95.1)$ & 0 & $5(4.9)$ & $24(88.9)$ & I (3.7) & $2(7.4)$ \\
\hline Streptomycin (STR) & $96(94.1)$ & I (I.0) & $5(4.9)$ & $25(92.6)$ & 0 & $2(7.4)$ \\
\hline Trimethoprim- sulfamethoxazole (SXT) & $63(61.8)$ & 0 & 39 (38.2) & $16(59.3)$ & 0 & II (40.7) \\
\hline Tetracycline (TET) & $64(62.7)$ & $\mathrm{I}(\mathrm{I} .0)$ & $37(36.3)$ & $15(55.6)$ & 0 & $12(44.4)$ \\
\hline
\end{tabular}

Abbreviations: S, sensitive; I, intermediate; $R$, resistance.

\section{Multi-Drug Resistance Profiles}

In this study, a total of $57(44.2 \%) E$. coli and E. coli O157: $H 7$ isolates were resistant to three or more classes of antibiotics. Multi-drug resistance profiles against three, four and five antibiotic classes were $34(26.4 \%), 19$ $(14.7 \%)$ and $4(3.1 \%)$, respectively. The frequency of resistant phenotype was more common for ampicillin and erythromycin, co-trimoxazole and tetracycline (Table 4). Statistically significant difference was observed in multidrug resistance pattern between E. coli and E. coli O157: H7, sample types and sample sources $(p \leq 0.001)$ (Table 5).

\section{Discussion}

Infections related to contaminated foods are major health problems, especially in developing countries, including Ethiopia. However, limited information was available on incidence and antimicrobials susceptibility pattern of the causative agents to helps policy makers to develop appropriate strategies in terms of prevention, treatment, and control. In this study, different samples such as meat of cattle, cecal content of slaughtered animals, swab samples taken from hands of meat handlers, and different surfaces that have contact with meat were tested for the presence of $E$. coli and E. coli O157: H7. Accordingly, E. coli were detected in 102 (20.2\%) of the samples tested, whereas E. coli O157: H7 were detected in 27 (5.4\%) of the samples. The proportion of positive samples in this study was higher than the previous study finding in different parts of Ethiopia. ${ }^{9,16-22}$ However, this finding is lower than the study finding in Ethiopia and other African countries. ${ }^{10,23-25}$ Another meta-analysis study showed that the overall prevalence of $E$. coli $\mathrm{O} 157$ : $\mathrm{H} 7$ was $31.20 \%$ in Africa and $1.65-7.35 \%$ in other continents. ${ }^{26}$ The observed differences might be due to the use of different methods of detections of isolates, differences in sample size, the type of sample and how and when it was collected. For instance, the use of immuno-magnetic separation and PCR technique may improve the sensitivity of the detection, which was not done in this study methodology.

With regard to sample source, $55(19.3 \%)$ and $17(6.0 \%)$ of samples from the abattoir house and $47(21.4 \%)$ and 10 (3.7\%) of samples from the butcher shops were positive for E. coli and E. coli O157: H7, respectively. Despite the differences in proportion of positive samples, the presence of E. coli and E. coli O157: $\mathrm{H} 7$ in abattoir and butcher shops samples were reported in many studies in Ethiopia. ${ }^{16-18,22,27-29}$ As compared to developed countries, this finding is higher than a finding in $\mathrm{USA}^{30}{ }^{30}$ in which the prevalence of E. coli $\mathrm{O} 157: \mathrm{H} 7$ on meat goat carcasses was $2.7 \%$. Moreover, other study on the safety and quality of pork and poultry meat imports for the common European market received at border inspection post Hamburg Harbour reported that, E. coli was present in $50 \%$ and $67 \%$ of all pork and poultry samples, respectively, and thereof 33 isolates were confirmed as extended-spectrum $\beta$-lactamaseproducing E. coli. ${ }^{31}$ The expected slight differences might 
Table 4 Multi-Drug Resistance Profiles of E. Coli and E. Coli OI57: H7 Isolates in Samples Obtained from Abattoir and Butcher Shops in Jimma Town, Southwest of Ethiopia

\begin{tabular}{|c|c|c|c|c|c|c|c|c|}
\hline \multirow{2}{*}{$\begin{array}{l}\text { Sources of } \\
\text { Isolates }\end{array}$} & \multirow[t]{2}{*}{ Resistance Patterns } & \multirow{2}{*}{$\begin{array}{l}\text { Antibiotics } \\
\text { Classes }\end{array}$} & \multicolumn{3}{|c|}{ Sources of MDR (\%) } & \multicolumn{2}{|c|}{ MDR Isolates (\%) } & \multirow{2}{*}{$\begin{array}{l}\text { Total } \\
\text { MDR }\end{array}$} \\
\hline & & & $\begin{array}{l}\text { Meat } \\
\text { Samples }\end{array}$ & $\begin{array}{l}\text { Ceacal } \\
\text { Content }\end{array}$ & $\begin{array}{l}\text { Swab } \\
\text { Samples }\end{array}$ & E. coli & $\begin{array}{l}\text { E. coli } \\
\text { OI57: H7 }\end{array}$ & \\
\hline $\begin{array}{l}\text { Abattoir house } \\
(n=72)\end{array}$ & $\begin{array}{l}\text { Abattoir house (N=72) } \\
\text { Amp, ERY, SXT } \\
\text { AMP, ERY, TET } \\
\text { AMP, ERY, SXT, TET } \\
\text { AMP, ERY, AMC, CXT, } \\
\text { SXT, TET } \\
\text { AMP, ERY, AMC, SXT, TET, } \\
\text { STR, GEN } \\
\text { Sub-Total MDR }\end{array}$ & $\begin{array}{l}\text { R3 } \\
\text { R3 } \\
\text { R4 } \\
\text { R4 } \\
\text { R5 }\end{array}$ & $\begin{array}{l}(\mathrm{n}=22) \\
3 \\
3 \\
2 \\
1 \\
0 \\
9\end{array}$ & $\begin{array}{l}(n=28) \\
3 \\
3 \\
2 \\
2 \\
2 \\
12\end{array}$ & $\begin{array}{l}(n=22) \\
3 \\
3 \\
1 \\
1 \\
0 \\
8\end{array}$ & $\begin{array}{l}(n=55) \\
7 \\
7 \\
4 \\
3 \\
1 \\
22\end{array}$ & $\begin{array}{l}(n=17) \\
2 \\
2 \\
1 \\
1 \\
1 \\
7\end{array}$ & $\begin{array}{l}(n=72) \\
9 \\
9 \\
5 \\
4 \\
2 \\
29 / 72\end{array}$ \\
\hline $\begin{array}{l}\text { Butcher shops } \\
(n=57)\end{array}$ & $\begin{array}{l}\text { Butcher shops }(\mathbf{N}=57) \\
\text { AMP, ERY, SXT } \\
\text { AMP, ERY, TET } \\
\text { AMP, ERY, SXT, TET } \\
\text { AMP, ERY, AMC, CXT, } \\
\text { SXT, TET } \\
\text { AMP, ERY, AMC, SXT, TET, } \\
\text { STR, GEN } \\
\text { Sub-Total MDR }\end{array}$ & $\begin{array}{l}\text { R3 } \\
\text { R3 } \\
\text { R4 } \\
\text { R4 } \\
\text { R5 }\end{array}$ & $\begin{array}{l}(n=31) \\
5 \\
4 \\
3 \\
2 \\
1 \\
15\end{array}$ & $\begin{array}{l}- \\
- \\
- \\
- \\
- \\
- \\
-\end{array}$ & $\begin{array}{l}(n=26) \\
3 \\
4 \\
3 \\
2 \\
1 \\
13\end{array}$ & $\begin{array}{l}(n=47) \\
6 \\
6 \\
4 \\
3 \\
2 \\
21\end{array}$ & $\begin{array}{l}(n=10) \\
2 \\
2 \\
2 \\
1 \\
0 \\
7\end{array}$ & $\begin{array}{l}(n=57) \\
8 \\
8 \\
6 \\
4 \\
2 \\
28 / 57\end{array}$ \\
\hline \multicolumn{3}{|c|}{ Overall MDR (\%) } & $24(45.3 \%)$ & $12(42.9 \%)$ & 21 (43.8\%) & $\begin{array}{l}43 \\
(42.2 \%)\end{array}$ & $14(51.8 \%)$ & $\begin{array}{l}57 \\
(44.2 \%)\end{array}$ \\
\hline
\end{tabular}

Abbreviations: R3-R5, resistance to three, four and five classes of antibiotics; AMP, ampicillin, CXT, cefotaxime, ERY, erythromycin, GEN, gentamicin, STR, streptomycin, SXT, trimethoprim-sulphamethoxazole, AMC, amoxicillin-clavulanic acid, TET, tetracycline.

Table 5 Analysis of MDR Profiles Based on Strain of Isolate, Samples Sources and Samples Types in Jimma Town, Southwest of Ethiopia

\begin{tabular}{|c|c|c|c|c|c|c|c|}
\hline \multicolumn{2}{|l|}{ Categories } & \multicolumn{3}{|c|}{ Number of Antibiotic Classes } & \multirow{2}{*}{$\begin{array}{l}\text { MDR/ } \\
\text { Total }\end{array}$} & \multirow[t]{2}{*}{ Prop. of MDR $[95 \% \mathrm{Cl}]$} & \multirow[t]{2}{*}{$p$-value } \\
\hline & & $\mathbf{R 3}$ & $\mathbf{R 4}$ & $\mathbf{R 5}$ & & & \\
\hline \multirow[t]{3}{*}{ Sample types } & Meat isolates $(n=53)$ & 15 & 8 & 1 & $24 / 53$ & $0.453[0.663,0.881]$ & 0.001 \\
\hline & Cecal isolates $(n=28)$ & 6 & 4 & 2 & $12 / 28$ & $0.429[0.56 \mathrm{I}, 0.876]$ & 0.012 \\
\hline & Swab sample isolates $(n=58)$ & 13 & 7 & 1 & $21 / 58$ & $0.362[0.473,0.720]$ & 0.118 \\
\hline \multicolumn{2}{|l|}{ Total MDR $[95 \% \mathrm{Cl}]$} & $34(26.4 \%)$ & $19(14.7 \%)$ & $4(3.1 \%)$ & $57 / 129$ & $0.442[0.575,0.821]$ & 0.003 \\
\hline \multirow[t]{2}{*}{ Sources of samples } & Abattoir house $(n=72)$ & 18 & 9 & 2 & $29 / 72$ & $0.403[0.579,0.790]$ & 0.001 \\
\hline & Butcher shops $(n=57)$ & 16 & 10 & 2 & $28 / 57$ & $0.491[0.724,0.916]$ & 0.001 \\
\hline \multicolumn{2}{|l|}{ Total MDR $[95 \% \mathrm{Cl}]$} & $34(26.4 \%)$ & $19(14.7 \%)$ & $4(3.1 \%)$ & $57 / 129$ & $0.442[0.593,0.885]$ & 0.004 \\
\hline \multirow[t]{2}{*}{ Strains of isolates } & E. coli $(n=102)$ & 26 & 14 & 3 & $43 / 102$ & $0.422[0.662,0.829]$ & 0.001 \\
\hline & E. coli OI57: H7 $(n=27)$ & 8 & 5 & 1 & $14 / 27$ & $0.518[0.586,0.897]$ & 0.007 \\
\hline \multicolumn{2}{|l|}{ Total MDR [95\% Cl] } & $34(26.4 \%)$ & $19(14.7 \%)$ & $4(3.1 \%)$ & $57 / 129$ & $0.442[0.678,0.826]$ & 0.001 \\
\hline
\end{tabular}

Abbreviations: R3-R5, resistance to three, four and five classes of antibiotics.

be due to the difference in hygienic conditions that could be risky for cross-contamination of meat and different contact surfaces with fecal materials during slaughtering, processing, transportation, and displaying at abattoir house and retailer shops. At all these stages, strict adherence to standard operating measures must be practiced. 
With regard to sample types, higher proportions of cecal contents of slaughtered animals were positive for $E$. coli and $E$. coli $\mathrm{O} 157: \mathrm{H} 7$ followed by meat and other different swab samples obtained from the abattoir and butcher shops. The presence of E. coli and E. coli O157: $\mathrm{H} 7$ in meat samples, cecal content and swab samples were also reported in different studies. ${ }^{9,16-23,27-32}$ Many reasons might be contributed for cross- contaminations of meat and surface contacts with cecal contents and other sources. Previous work in cattle suggests that the prevalence of E. coli $\mathrm{O} 157: \mathrm{H} 7$ in the feces is correlated to the prevalence on the hide and carcasses of animals at slaughter. ${ }^{33,34}$ In the present study, poor hygienic practices of the abattoir house and butcher shops' workers observed were found to be risky for contamination of meat with E. coli and E. coli O157: H7. This condition is more risky in our situation; because of the widespread practice of raw meat consumption throughout the country. Studies concluded that, raw meat can harbor harmful pathogenic E. coli $\mathrm{O} 157$ : $\mathrm{H} 7$ causing diarrhoea and systemic manifestations such as hemorrhagic colitis, hemolytic uremic syndrome (HUS). ${ }^{6,35,36}$

E. coli O157: $\mathrm{H} 7$ carriage in the intestinal tract of healthy animals, particularly cattle, represents a source of direct and indirect infection to humans. Contamination of meat with fecal material in the slaughtering process and during displaying of meat for sale is the main transmission route of bacteria. It is a well documented fact that, lack of education and training on food safety may contribute for unhygienic practices such as improper handling, processing and display of meat at the slaughtering places and at butcher shops. ${ }^{18,27-29,37}$ In this study, none of the abattoir and butcher shop workers had a formal education certificate on food safety or short course training on safe meat handling. Moreover, workers at the slaughter house were not well supplied with materials that would enable them to maintain general hygiene. For instance, inadequate supply of clean water is one of the greatest challenges to maintain hygiene. That is why; risky practices during the slaughtering, transportation and display of meat were observed and documented in the present study. Thus, the presence of E. coli and E. coli $\mathrm{O} 157: \mathrm{H} 7$ on meat might be due to transfer of fecal material onto the carcass during the slaughter process or from different contaminated materials and hands of meat handlers. This may occur with currently available dressing procedures at the abattoir house and further meat processing at butcher shops cannot be reliable to prevent fecal and cross-contamination of meat. Therefore, the range of activities should be carried out with the appropriate training on knowledge and hygienic practices of meat handlers.

In this study, the antimicrobial resistance pattern of isolates were checked with different classes of antibiotics. Accordingly, a total of $57(44.2 \%)$ E. coli and E. coli O157: $H 7$ isolates were resistant to three or more classes of antibiotics. The prevalence of multi-drug resistant isolates was also reported in many previous studies, ${ }^{9,16,21,22,29,38}$ in which about $(33.2 \%$ to $100 \%)$ of isolates were showed multidrug resistance. The occurrence of multidrug resistance may be linked with indiscriminate utilization of antimicrobial agents or genetic mutation, which was not elucidated with the present study methodology. Moreover, transmission of multi-drug resistant bacteria via consumption of meat and meat products has been suggested as a potential source in Africa. ${ }^{39,40}$

In this study, third generation cephalosporin (cefotaxime, ceftriaxone and cefotaxime), gentamicin, ciprofloxacin, kanamycin, streptomycin and chloramphenicol showed best activities against our isolates. In contrast, higher resistance was observed against erythromycin and ampicillin, followed by tetracycline, co-trimoxazole and amoxicillin-clavulanic acid. The best efficacies and high resistance rate against the above antibiotics were also reported in previous studies in Ethiopia and Iran. ${ }^{9,16-18,29,32,38,41}$ The higher resistance rate might be due to inappropriate and excessive use of these antibiotics for therapeutic and prophylactic purposes both in human and animal infections. In fact, the frequent and misuse of antibiotics in humans and food animals is closely linked to the recent emergence of multi-drug resistant bacteria. This may lead to increased load of antibiotics, poor clinical outcome, and limited therapeutic options.

In the current study, although molecular techniques such as PCR is more accurate for identification of E. coli and E. coli $\mathrm{O} 157: \mathrm{H} 7$ and antimicrobial resistance testing, due to unavailability, phenotypic methods were used for identification and antimicrobial resistance testing of isolates.

\section{Conclusion}

This study indicated that, multi-drug resistant $E$. coli and E. coli $\mathrm{O} 157$ : $\mathrm{H} 7$ isolates were more common. In addition, poor hygienic practices of meat handlers were observed, which may have implications for cross-contaminations of meat. Therefore, improving knowledge and practice of abattoir and butcher shop workers about safe meat handling and distribution as well as monitoring antibiotics use in human and animal health may have great implications 
in prevention and control of food-borne infections that may be caused by antibiotic-resistant strains.

\section{Data Sharing Statement}

All the data supporting our findings were incorporated within the manuscript.

\section{Ethical Approval and Consent to Participate}

Ethical approval was obtained first from Jimma University Review Board, rather than from my own institution, because the study was conducted when I was an MSc student at Jimma University by the invitation of Onehealth project. At the time, One-health project office was found in Jimma University and invited MSc students to submit animal-related proposals and the project was facilitated by the ethical approval issues by communicating with Jimma University Review Board. Official permission was also sought from Jimma town municipal administration. All abattoir workers, butchers and meat retailer shop owners provided informed consent prior to participating in this study which was performed in accordance with the Declaration of Helsinki.

\section{Acknowledgment}

First, we would like to thank Jimma University for giving permission of the laboratory setup with necessary supplies. Secondly, we would like to thank One-health Central and East African project. We also thank all the data collectors and study participants at the abattoir house and meat retailer shops for participating in this study.

\section{Author Contributions}

Authors (MA and ET) made substantial contributions to conception and design, acquisition of data, or analysis and interpretation of data; took part in drafting the article or revising it critically for important intellectual content; agreed to submit to the current journal; gave final approval of the version to be published; and agree to be accountable for all aspects of the work.

\section{Funding}

No funding was allocated for this study.

\section{Disclosure}

The authors report no conflicts of interest in this work.

\section{References}

1. Lupindu AM. Epidemiology of Shiga toxin-producing Escherichia coli O157: h7in Africa in review. Southern African J Infect Dis. 2018;33(1):24-30. doi:10.1080/23120053.2017.1376558

2. Stein RA, Katz DE. Escherichia coli, cattle and the propagation of disease. FEMS Microbiol Lett. 2017;364(6). doi:10.1093/femsle/ fnx 050

3. Howie H, Mukerjee A, Cowden J, et al. Investigation of an outbreak of Escherichia coli $\mathrm{O} 157$ infection caused by environmental exposure at a scout camp. Epidemiol Infect. 2003;131(3):1063-1069. doi:10. 1017/S0950268803001250

4. Caprioli A, Morabito S, Brugère H, et al. Enterohaemorrhagic Escherichia coli: emerging issues on virulence and modes of transmission. Vet Res. 2005;36(3):289-311. doi:10.1051/vetres:2005002

5. Majowicz SE, Scallan E, Jones-Bitton A, et al. Global incidence of human shiga toxin-producing Escherichia coli infections and deaths: a systematic review and knowledge synthesis. Food Borne Pathog Dis. 2014;11(6):447-455. doi:10.1089/fpd.2013.1704

6. Spickler AR. 2016. Enterohemorrhagic Escherichia coli Infections. Retrieved from http://www.cfsph.iastate.edu/DiseaseInfo/factsheets. php. Accessed October 2, 2020.

7. Bello M, Lawan MK, Aluwong T, Sanusi M. Management of slaughter houses in northern Nigeria and the safety of meat produced for human consumption. Food Control. 2015;49:34-39. doi:10.1016/j. foodcont.2013.09.007

8. McEvoy JM, Doherty AM, Sheridan JJ, et al. The prevalence and spread of Escherichia coli O157: h7at a commercial beef abattoir. $J$ Appl Microbiol. 2003;95(2):256-266. doi:10.1046/j.1365-2672.2003.01981.x

9. Dulo F, Feleke A, Szonyi B, Fries R, Baumann MPO, Grace D. Isolation of multidrug-resistant Escherichia coli $\mathrm{O} 157$ from Goats in the Somali Region of Ethiopia: a cross-sectional, abattoir-based study. PLoS One. 2015;10(11):e0142905. doi:10.1371/journal.pone. 0142905

10. Mersha G, Asrat D, Zewde BM, et al. Occurrence of Escherichia coli O157:H7 in faeces, skin and carcasses from sheep and goats in Ethiopia. Lett Appl Microbiol. 2010;50(1):71-76. doi:10.1111/lam. 2009.50.issue-1

11. Okeke IN, Laxminarayan R, Bhutta ZA, et al. Antimicrobial resistance in developing countries. Part I: recent trends and current status. Lancet Infect Dis. 2005;5(8):481-493. doi:10.1016/S1473-3099(05) 70189-4

12. ISO 16654. Microbiology - Horizontal Method for the Detection of Escherichia Coli O157. Geneve, Switzerland: International Organization for Standardization; 2001.

13. United States Department of Agriculture (USDA) Food Safety and Inspection Service. Laboratory Guidebook on detection, isolation and identification of Escherichia coli O157: H7from meat products and carcass and environmental sponges. 2013:1-14.

14. CLSI. Performance Standards for Antimicrobial Susceptibility Testing; Twenty-Fourth Informational Supplement. CLSI Document M100-S24. Wayne, PA: Clinical and Laboratory Standards Institute; 2014.

15. Magiorakos A, Srinivasan A, Carey RB, et al. Bacteria: an international expert proposal for interim standard definitions for acquired resistance. Clin Microbiol Infect. 2011;18:268-281. doi:10.1111/ j.1469-0691.2011.03570.x

16. Atnafie B, Paulos D, Abera M, Tefera G, Hailu D, Kasaye S. Occurrence of Escherichia coli O157: H7 in cattle feces and contamination of carcass and various contact surfaces in abattoir and butcher shops of Hawassa, Ethiopia. BMC Microbiol. 2017;14 (17):1-7. doi:http://dx.doi.10.1186/s12866-017-0938-1.

17. Abdissa R, Haile W, Fite AT, et al. Prevalence of Escherichia coli O157: $\mathrm{h} 7$ in beef cattle at slaughter and beef carcasses at retail shops in Ethiopia. BMC Infect Dis. 2017;17(1):277. doi:10.1186/s12879$017-2372-2$ 
18. Mengistu S, Abayneh E, Shiferaw D. E. coli O157: h7and Salmonella species: public health importance and microbial safety in beef at selected slaughter houses and retail shops in Eastern Ethiopia. $J$ Vet Sci Technol. 2017;8(5):468. doi:10.4172/2157-7579.1000468

19. Taye M, Berhanu T, Berhanu Y, Tamiru F, Terefe D. Study on carcass contaminating Escherichia coli in apparently healthy slaughtered cattle in Haramaya University Slaughter House with special emphasis on Escherichia coli O157: H7, Ethiopia. J Veterinar Sci Technol. 2013;4(1):132. doi:10.4172/2157-7579.1000132

20. Beyi AF, Fite AT, Tora E, et al. Prevalence and antimicrobial susceptibility of Escherichia coli O157 in beef at butcher shops and restaurants in central Ethiopia. BMC Microbiol. 2017;17(1):49. doi:10.11 86/s12866-017-0964-z

21. Bedasa S, Shiferaw D, Abraha A, Moges T. Occurrence and antimicrobial susceptibility profile of Escherichia coli O157:H7 from food of animal origin in Bishoftu town, Central Ethiopia. Int $\mathrm{J}$ Food Contamination. 2018;5(1):2. doi:10.1186/s40550-018-0064-3

22. Hiko A, Asrat D, Zewde G. Occurrence of Escherichia coli O157: h7in retail raw meat products in Ethiopia. J Infect Dev Ctries. 2008;2 (5):389-393.

23. Bekele T, Zewde G, Tefera G, Feleke A, Zerom K, Escherichia coli O157: H7 in raw meat in Addis Ababa, Ethiopia: prevalence at an abattoir and retailers and antimicrobial susceptibility. Int $J$ Food Contamination. 2014;1(1):4. doi:10.1186/s40550-014-0004-9

24. Kiranmayi CHB, Krishnaiah N. Detection of Escherichia coli O157: $\mathrm{h} 7$ prevalence in foods of animal origin by cultural methods and PCR technique in Hyderabad. Veterinary World. 2010;3(1):13-16.

25. Beneduce L, Spano G, Nabi AQ, et al. Occurrence and characterization of Escherichia coli $\mathrm{O} 157$ and other serotypes in raw meat products in Morocco. J Food Protect. 2008;71(10):2082-2086. doi:10.4315/0362-028X-71.10.2082

26. Islam MZ, Musekiwa A, Islam K, et al. Regional variation in the prevalence of E. coli $\mathrm{O} 157$ in cattle: a meta-analysis and meta-regression. PLoS One. 2014;9(4):e93299. doi:10.1371/journal. pone.0093299

27. Bersisa A, Tulu D, Negera C. Investigation of bacteriological quality of meat from abattoir and butcher shops in Bishoftu, Central Ethiopia. Int J Microbiol. 2019;6416803:8. doi:10.1155/2019/6416803

28. Dulo F. Prevalence and Antimicrobial Resistance Profile of Escherichia Coli O157: H7 in Goat Slaughtered in Dire Dawa Municipal Abattoir as Well as Food Safety Knowledge, Attitude and Hygiene Practice Assessment Among Slaughter Staff. Ethiopia. Addis Ababa: Addis Ababa University; 2014.

29. Afera B, Kebede T, Taddele H, Bisrat A. Assessment of bacteriological quality of sold meat in the butcher shops of Adigrat, Tigray, Ethiopia. Appl J Hyg. 2014;3(3):38-44.

30. Jacob ME, Foster DM, Rogers AT, Balcomb CC, Sanderson MW. Prevalence and relatedness of Escherichia coli O157: h7strains in the feces and on the hides and carcasses of U.S. meat goats at slaughter. Appl Environ Microbiol. 2015;81(1):462. doi:10.1128/AEM.03561-14
31. Jansen W, Woudstra S, Müller A, et al. The safety and quality of pork and poultry meat imports for the common European market received at border inspection post Hamburg Harbour between 2014 and 2015. PLoS One. 2018;13(2):e0192550. doi:10.1371/journal. pone. 0192550

32. Mohammed O, Shimelis D, Admasu P, Feyera T. Prevalence and antimicrobial susceptibility pattern of $E$. coli isolates from raw meat samples obtained from abattoirs in Dire Dawa City, Eastern Ethiopia. Int J Microbiol Res. 2014;5(1):35-39. doi:10.5829/idosi.ijmr.2014. 5.1 .82306

33. Mekonnen H, Habtamu T, Kelali A, Shewit K. Food safety knowledge and practices of abattoir and butchery shops and the microbial profile of meat in Mekelle City, Ethiopia. Asian Pac J Trop Biomed. 2013;3(5):407-412. doi:10.1016/S2221-1691(13)60085-4

34. Elder RO, Keen JE, Siragusa GR, Barkocy-Gallagher GA, Koohmaraie M, Laegreid WW. Correlation of enterohemorrhagic Escherichia coli 0157 prevalence in feces, hides, and carcasses of beef cattle during processing.Proce Nat Acad Sci. 2000;97 (7):2999-3003. doi:10.1073/pnas.97.7.2999

35. Jacob ME, Renter DG, Nagaraja TG. Animal- and truckload-level associations between Escherichia coli O157:H7 in feces and on hides at harvest and contamination of preevisceration beef carcasses $\dagger$. J. Food Prot. 2010;73(6):1030-1037. doi:10.4315/0362-028X-73.6. 1030

36. Sethulekshmi C, Latha C, Sunil B. Occurrence of enterohaemorrhagic $E$. coli in raw meat samples in Kerala, India. Int $J$ Adv Res Biol Sci. 2016;3(1):220-222.

37. Girma G, Ketema T, Bacha K, Microbial load and safety of paper currencies from some food vendors in Jimma Town, Southwest Ethiopia. BMC Res Notes. 2014;7(1):843. doi:10.1186/1756-05007-843

38. Abayneh M, Tesfaw G, Woldemichael K, et al. Assessment of extended-spectrum $\beta$-lactamase (ESBLs) - producing Escherichia coli from minced meat of cattle and swab samples and hygienic status of meat retailer shops in Jimma town, Southwest Ethiopia. BMC Infect Dis. 2019;19(1):897. doi:10.1186/s12879-019-4554-6

39. Alonso CA, Zarazaga M, Ben Sallem R, Jouini A, Ben Slama K, Torres C. Antibiotic resistance in Escherichia coli in husbandry animals: the African perspective. Lett Appl Microbiol. 2017;64 (5):318-334. doi:10.1111/lam.12724

40. Eibach D, Dekker D, Gyau Boahen K, et al. Extended-spectrum beta-lactamase-producing Escherichia coli and Klebsiella pneumoniae in local and imported poultry meat in Ghana. Vet Microbiol. 2018;217:7-12. doi:10.1016/j.vetmic.2018.02.023

41. Mashak Z. Prevalence and antibiotic resistance of Escherichia coli O157: h7 isolated from raw meat samples of ruminants and poultry. J Food Nutrition Res. 2018;6(2):96-102. doi:10.12691/jfnr-6-2-5
Infection and Drug Resistance

\section{Publish your work in this journal}

Infection and Drug Resistance is an international, peer-reviewed openaccess journal that focuses on the optimal treatment of infection (bacterial, fungal and viral) and the development and institution of preventive strategies to minimize the development and spread of resistance. The journal is specifically concerned with the epidemiology of antibiotic resistance and the mechanisms of resistance development and diffusion in both hospitals and the community. The manuscript management system is completely online and includes a very quick and fair peerreview system, which is all easy to use. Visit http://www.dovepress.com/ testimonials.php to read real quotes from published authors. 